JOURNAL DE PHYSIQUE IV

Colloque C4, supplément au Journal de Physique III, Vol. 1, novembre 1991

\title{
ALLOYS OF IRON AND REVERSIBILITY OF MARTENSITIC TRANSFORMATIONS
}

\author{
E. HORNBOGEN and N. JOST \\ Institut für Weskstoffe, Ruhr-Universtität Bochum, Postfach 10, 21 48, D-4630 Bochum 1, \\ Germany
}

\begin{abstract}
The origin of irreversibility, reversibility, course and completeness of martensitic transformations are discussed using the following alloys of iron as examples:

1. Irreversible transformation: $\mathrm{Fe}-\mathrm{C}, \mathrm{Fe}-\mathrm{Ni}-\mathrm{C}$, maraging steel

2. Reversibility in homogeneous solid solutions: $\mathrm{Fe}-\mathrm{Ni}, \mathrm{Fe}-\mathrm{Ni}-\mathrm{C}, \mathrm{Fe}-\mathrm{Mn}$

3. Reversibility due to order or coherent particles: $\mathrm{Fe}-\mathrm{Pt}, \mathrm{Fe}-\mathrm{Ni}-\mathrm{X}, \mathrm{Fe}-\mathrm{Ni}-\mathrm{Co}-\mathrm{Ti}$

4. Effects of external stress and mechanical properties on $\mathbf{M}_{\mathbf{S}}$

5. Effects of external magnetic fields and magnetism/antiferromagnetism in austenite.

The feasibility of shape memory steels is finally discussed.
\end{abstract}

\section{Introduction}

Hardening of carbon steels and the phase transformation which takes place during such a heat treatment has been utilized by mankind for a long period of time." The name "martensitic transformation"2) for this particular first order structural phase transformation is used not only for carbon steels, but also for non-ferrous and even non-metallic materials. ${ }^{3}$ ? The transformation in steels is least suitable to demonstrate a quantitative physical understanding because of its complexity. Alloys of iron on the other hand do provide information on all typical aspects, as well as important side-effects, of this unique solid state reaction. Examples for important features are:

1. large amounts $\left(\gamma_{\gamma \alpha}>0.2\right)$ of homogeneous lattice variant shear,

2. various modes of lattice invariant shear,

3. volume change of different signs, $\mathrm{v}_{\gamma \alpha}>0$ in $\mathrm{Fe}-\mathrm{Ni}, \mathrm{v}_{\gamma \epsilon}<0$ in $\mathrm{Fe}-\mathrm{Mn}$,

4. diffusion of interstitial atoms interfering with non-diffusive atomic motions,

5. interference of paramagnetic $\mapsto$ ferromagnetic, or paramagnetic $\mapsto$ antiferromagnetic transformation with the martensitic transformation,

6. effects of precipitation, ordering and premartensitic second order transformations in austenite $(\gamma)$ on the subsequent transformation.

Therefore, studies of iron alloys can be very useful for a comprehensive and qualitative understanding of martensitic transformation. Such a better understanding could provide a base for an improvement of known technological processes or even completely new developments such as:

a) the effects of stresses acting during the transformation and austenitization of tool steels,

b) the mechanism of surface hardening by friction-induced transformation,

c) transformation-induced plasticity,

d) shape-memory due to reversible transformation,

e) a high damping capacity for mechanical vibrations.

Many reviews of martensitic transformation in iron alloys have been given earlier.4) We will emphasize aspects which have received less attention but which are of relevance for a comprehensive understanding of the question of why and at what temperatures does a martensitic structure revert martensitically into austenite. As martensitic transformation is not reversible in structural 
steels and tool steels, the answer to the question of reversibility should provide guidance for the development of highly damping or shape memory steels.

2. Irreversible transformation, $\mathrm{Fe}-\mathrm{C}, \mathrm{Fe}-\mathrm{Ni}-\mathrm{C}$, maraging steel

It has been pointed out earlier that martensitic transformation in carbon steels requires considerable undercooling $\Delta \mathrm{T}$ below the equilibrium temperature $\mathrm{T}_{0}$ to initiate the transformation at $\mathrm{M}_{\mathrm{s}}$ $\left(\Delta \mathrm{T} \geq 200^{\circ} \mathrm{C}\right)^{5)}$ :

$$
\mathrm{M}_{\mathrm{s}}=\mathrm{T}_{0}-\Delta \mathrm{T}
$$

The dependence of $\mathrm{M}_{\mathrm{s}}$ on the carbon content shows a course about parallel to the $\mathrm{T}_{0}$-temperature (approximately obtained as the center of the $\gamma / \alpha$-equilibrium functions in the $\mathrm{Fe}-\mathrm{C}$ diagram, Fig. 1).

$$
\mathrm{C}_{0}\left(\mathrm{~T}_{0}\right) \approx \mathrm{C}_{\alpha}+\left(\frac{\mathrm{C}_{\gamma}+\mathrm{C}_{\alpha}}{2}\right)
$$

Transformation temperatures $\mathrm{M}_{\mathrm{s}}<20^{\circ} \mathrm{C}$ require high $(>2 \mathrm{wt} \%$ ) carbon contents, which are kept in $\gamma$-solid solution only by rapid cooling from the liquid (Fig. 2).

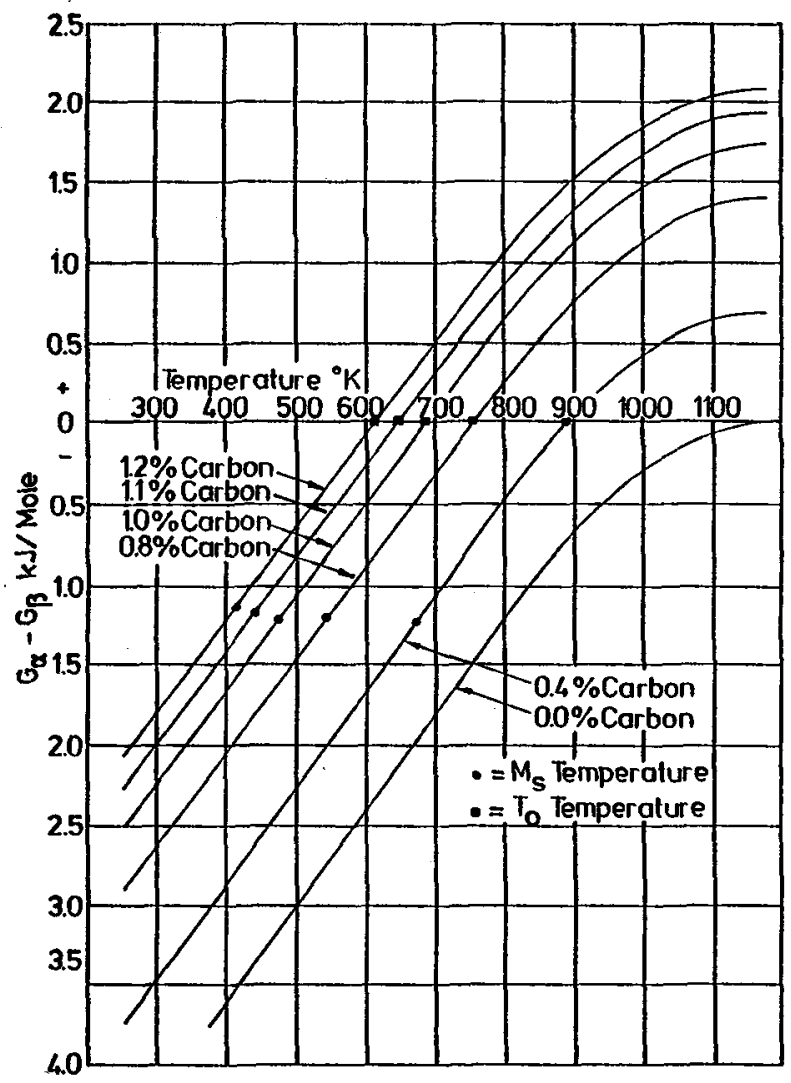

Fig. 1: Change in chemical free energy associated with the autenite-martensite reaction in $\left.\mathrm{Fe}-\mathrm{C}^{5}\right)$

The following reactions can take place inside $\mathrm{Fe}-\mathrm{C}-$ martensite in the environment of ambient temperature: 


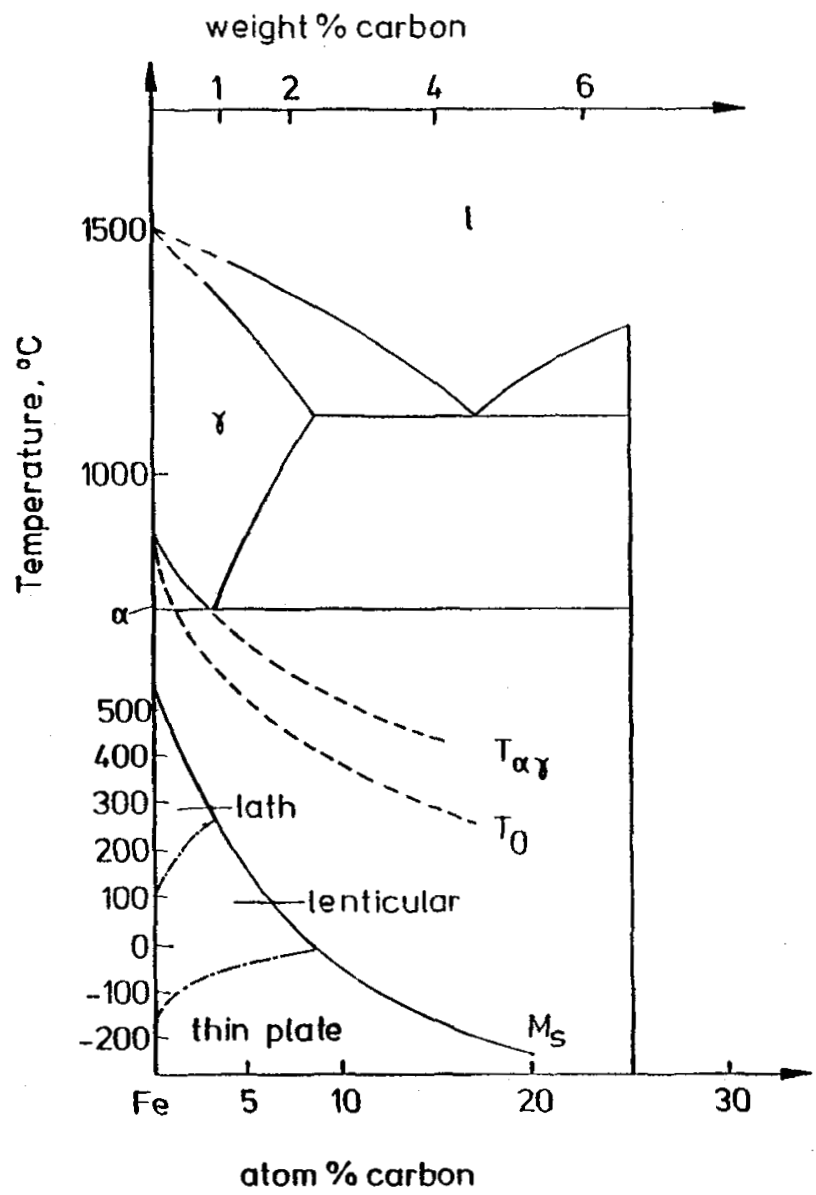

Fig. 2: Simplified phase diagram $\mathrm{Fe}_{3} \mathrm{C}$ including the martensite temperatures and morphologies in dependence of the $\mathrm{C}$-content and transformation temperature

a) reaction of $\frac{a}{2}<111>$ dislocations which originated by lattice invariant shear to immobile nodes

$$
\frac{\mathrm{a}}{2}[1 \overline{1} 1]+\frac{\mathrm{a}}{2}[11 \overline{1}]+\frac{\mathrm{a}}{2}[100]
$$

b) segregation of carbon atoms to the distocations in martensite $\alpha_{\mathrm{d}}$

$$
\alpha_{\mathrm{d}}+\mathrm{C} \rightarrow \alpha_{\mathrm{d}-\mathrm{C}}
$$

c) precipitation of various carbides or intermetallic compounds (for example: maraging steel):

$$
\begin{aligned}
& \alpha_{M} \rightarrow \alpha+\mathrm{Fe}_{\mathrm{x}} \mathrm{C}_{\mathrm{y}} \\
& \alpha_{\mathrm{M}} \rightarrow \alpha+\mathrm{Fe}_{\mathrm{X}} \mathrm{X}_{\mathrm{y}}
\end{aligned}
$$

d) intersection zones of martensite plates

These reactions counteract a restauration of the original austenite crystal by a reverse martensitic reaction. The two principle ways for reformation of austenite are: 


$$
\begin{aligned}
& \alpha_{\mathrm{M}} \frac{\text { new nucleation of }}{\text { aus tenite crystals }} \gamma_{\text {fine-grain }} \\
& \alpha_{\mathrm{M}} \frac{\text { r everse motion of all }}{\text { martensi te crystals }} \gamma_{\text {unchanged grain size or single crystal }}
\end{aligned}
$$

Reaction (6a) is especially enforced, if precipitation in martensite (equ. 5) preceedes the formation of austenite. On the other hand, the reactions (3)-(5) should be avoided if reversibility is aspired. Irreversibility of the transformation is a typical feature of lath martensite found in low carbon steels, $\mathrm{Fe}-\mathrm{Ni}$ with less than 20 at.\% $\mathrm{Ni}$ and corresponding $\mathrm{Fe}-\mathrm{Ni}-\mathrm{C}$ or $\mathrm{Fe}-\mathrm{Ni}-\mathrm{Mn}$ alloys, all with $\mathrm{M}_{\mathrm{s}}>200^{\circ} \mathrm{C}$. A rather straight and a rugged boundary of the martensite crystals indicated its one-sided motion. The habit plane scatters around $\{111\}_{\gamma}$ by $\pm 6^{\circ}$. An analysis of the structure of the highly coherent $\gamma / a$-interface provides proof for a glissile nature provided by narrowly spaced $(2-6 \mathrm{~nm})$ partial dislocations. Its reverse motion is inhibited by the intracrystalline dislocations in the martensitic phase (equ. 3 and 4$) .6)$

3. Reversibility in homogeneous solid solutions: $\mathrm{Fe}-\mathrm{Ni}, \mathrm{Fe}-\mathrm{Ni}-\mathrm{C}, \mathrm{Fe}-\mathrm{Mn}$

There are early reports on the reversibility of the reverse reaction $\alpha_{M} \rightarrow \gamma$ (equ. 6b) from the analysis of textures. ${ }^{7)}$ Partial or total crystallographic reversibility is favoured by a high rate of heating and low transformation temperatures. ${ }^{8-9)}$ An $\mathrm{Fe}-32.5$ at.\% $\mathrm{Ni}$ alloy $\left(\mathrm{M}_{\mathrm{S}}=-90{ }^{\circ} \mathrm{C}\right)$ for example developed surface upheavals on polished martensite, when heated to $\mathrm{T}>30{ }^{\circ} \mathrm{C}>\mathrm{A}_{\mathrm{s}}$. This indicates the dominating role of shear up to a temperature range in which diffusion of substitutional elements becomes considerable. It was however reported, that the original orientation of all austenite crystals was not completely reestablished (Fig. 3). Dislocation networks were found in the reformed austenite. Different from tool steels, precipitation does not interfere with retransformation in stable solid solutions. But even $\mathrm{Fe}-\mathrm{Ni}-\mathrm{C}$ alloys can acquire a high degree of reversibility if the transformation temperatures are sufficiently low (Fig. 2). This could be established by surface trace analysis of $\mathrm{Fe}-33.7 \mathrm{wt} . \% \mathrm{Ni}$ with $0.4-0.8 \mathrm{wt} . \% \mathrm{C} .{ }^{9)}$ Reverse transformation can take place not only by reverse motion of $\gamma / \alpha$-interfaces, but also by nucleation of the $\gamma$-phase inside martensite plates. Tetragonality of the martensite in the $\mathrm{C}$-containing alloy is used to explain the

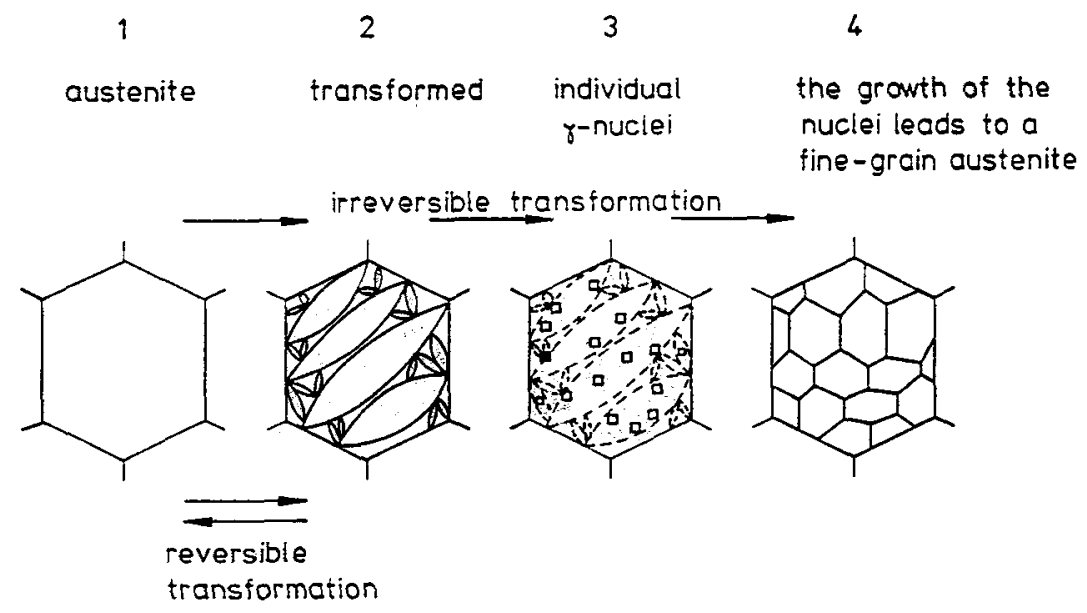

Fig. 3: Two modes of the reformation of austenite: 1) mobile $\gamma / \alpha$-interfaces $\rightarrow$ reversibility and shape memory; 2) new nucleation of austenite crystals $\rightarrow$ irreversibility 
high amount of reversibility. It was also observed that reversion of stress-induced martensite was more complete than of thermal martensite. This should be due to back-stresses and provides a base for a one way shape memory effect.

A similar effect can be obtained in Fe-Mn-X alloys. It is well known that the martensitic transformation shifts from $\mathrm{fcc} \rightarrow \mathrm{bct}(\alpha)$ to $\mathrm{fcc} \rightarrow \mathrm{hcp}(\epsilon)$ above $10 \mathrm{wt} . \% \mathrm{Mn}$. Different from bcc or bct $\alpha$-martensite $\epsilon$-martensite increases its density because it is antiferromagnetic. It formes by a simple change of stacking sequence with $\{111\}_{\gamma}$-habit without lattice invariant shear. Third alloying elements $X$ allow to modify the transformation temperatures. The temperature range $\Delta T_{h}$ (hysteresis) between $M_{s}$ and $A_{S}$ is not sensitive to the alloy composition. A second effect of third solutes $\mathrm{X}$ is solid solution strengthening of the $\gamma$-phase. It is important, if forces are to be exerted in shape memory (Figs. 4,5). The $\gamma \rightarrow \epsilon$-transformation never reaches the same degree of completeness like $\beta \rightarrow \alpha-$ and $\gamma \rightarrow \alpha-$ martensitic transformations. The reason is the absence of lattice invariant strain and consequent elastic restraint, which, in turn, favours the reverse transformation. ${ }^{10)}$
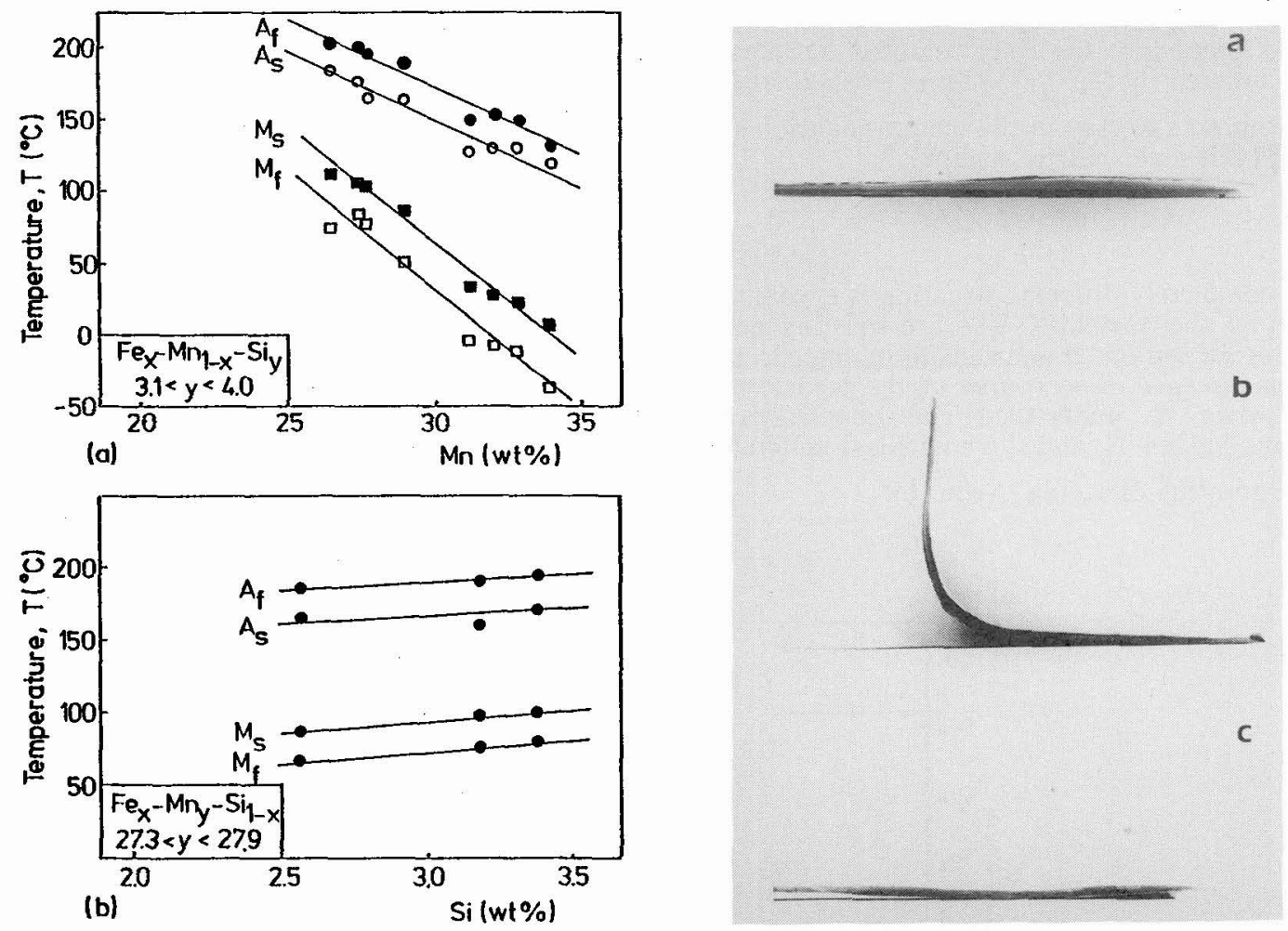

Fig. 5: Shape memory effect in a melt-spun

Fig. 4: Influence of $\mathrm{Mn}-$ and $\mathrm{Si}-$ contents on the transformation temperature in $\mathrm{Fe}-\mathrm{Mn}-\mathrm{Si}$ alloys Fe-Mn-Si ribbon

4. Reversibility due to order or coherent particles: $\mathrm{Fe}-\mathrm{Pt}, \mathrm{Fe}-\mathrm{Ni}-\mathrm{X}, \mathrm{Fe}-\mathrm{Ni}-\mathrm{Co}-\mathrm{Ti}$

The results discussed in chpts. 3 and 4 disprove that an ordered solid solution is a necessary prerequisite for reversible transformation. A comparison of a $\psi$-solid solution of the same composition in the disordered and ordered state can be made with Fe-Pt alloys (Fig. 6). 11) Alloys with Ptcontents less than the stochiometric composition $\mathrm{Fe}_{3} \mathrm{Pt}$ (ordering temperature $\mathrm{T}_{\Omega}=835^{\circ} \mathrm{C}$ ) can 
be obtained in different degrees of order $0<\mathrm{S}<1$ by quenching or slow cooling from above this temperature, or by aging at about $650^{\circ} \mathrm{C}$. This alloy shows a small volume change due to an "invar" effect 11 20) (see chapter 6). The microstructure of martensite formed from disordered FePt corresponds to that of $\mathrm{Fe}-\mathrm{Ni}$ based alloys (chpt. 2,3). An increasing amount of order lowers $M_{s}$ and leads to finer $\{112\}$-twinning as compared to the disordered structure. The major difference is the transition to a tetragonal crystal structure of the martensite as a direct consequence of the lattice variant shear from the $\mathrm{Fe}_{3} \mathrm{Pt}$-structure (Fig. 7). Associated with transition to order is a reduced hysteresis and complete crystallographic reversibility of the transformation. ${ }^{12}$ )

Closely related to the behavior of $\mathrm{Fe}-\mathrm{Pt}$ alloys are the observations made much earlier with $\mathrm{Fe}-\mathrm{Ni}-\mathrm{X}$ alloys $(\mathrm{X}=\mathrm{Cu}, \mathrm{Al}, \mathrm{Si}, \mathrm{Ti})$ which are due to coherent precipitation of a disordered $(\mathrm{Cu})$ or ordered $\left(\mathrm{Ni}_{3} \mathrm{Al}\right.$ ) phase in austenite above $\mathrm{M}_{\mathrm{s}}$ (Fig. 8). ${ }^{13-15)}$ The martensite morphology is changed as isothermal ageing leads from the homogeneous solid solution to the overaged state (compare Fig. 2):

$$
\text { lath } \rightarrow \text { lenticular } \rightarrow \text { thin plate } \rightarrow \text { fine lenticular }
$$

Transmission electron microscopy reveals formation of coherent particles with increasing volume fractions and size as it is well known for precipitation and subsequent coarsening. The particles are forced into the body centered coordination, no matter whether they are disordered (bcc- $\mathrm{Cu}$ ) or ordered (bct-Ni ${ }_{3} \mathrm{Al}$ ). There exists a critical particle size $d_{c}$ above which it is energetically more favourable to stay in the fcc coordiantion and consequently to form a non-coherent interface (Fig. 9), ( $\mathrm{C}$ is a geometrical factor):

$$
\mathrm{d}_{\mathrm{c}} \geq \frac{\gamma_{\mathrm{nc}}-\gamma_{\mathrm{c}}}{\Delta \mathrm{G}_{\gamma \alpha}}
$$

A completely different situation is encountered, if coherency has been lost already during tempering of the austenite. The pre-existing non-coherent interfaces may form additional nucleation sites for lenticular martensite or impede propagation of the transformation interfaces which become rugged. The course of the transformation temperature appears complex (Fig. 10). It can however be understood and quantitatively analyzed, if the thermo-dynamical equilibrium temperature $\mathrm{T}_{0}$ and the additional undercooling $\Delta \mathrm{T}$ are regarded as two independant functions of he duration of ageing $t$ (equ. 1).

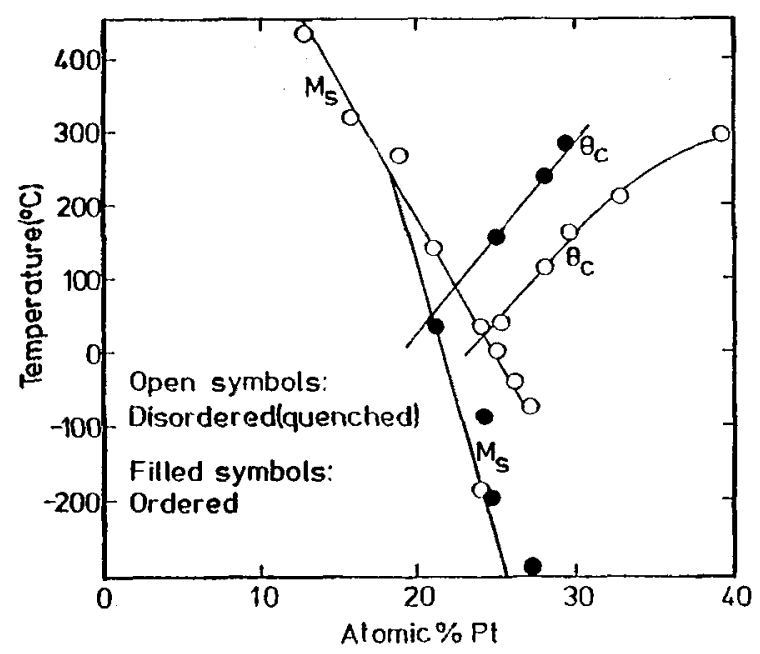

Fig. 6: Variation of Curic-temperature and martensite start temperature with $\mathrm{Pt}$-content in ordered and disordered $\mathrm{Fe}-\mathrm{Pt}-$ solid solutions ${ }^{11}$ 


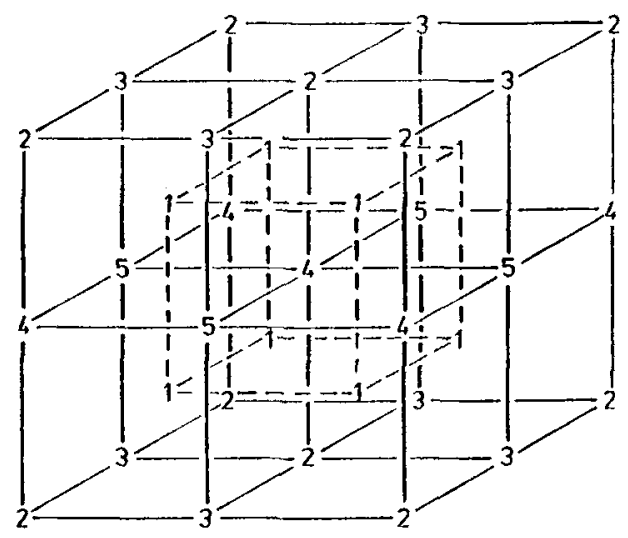

\begin{tabular}{|c|c|c|c|}
\hline \multirow{2}{*}{\multicolumn{2}{|c|}{ phase }} & \multicolumn{2}{|c|}{ atom-positions } \\
\hline & & $\mathrm{Fe}, \mathrm{Ni}$ & Al \\
\hline $\begin{array}{l}\text { (Fe, Ni) Al } \\
(\mathrm{Fe}, \mathrm{Ni})_{3} \mathrm{Al} \\
(\mathrm{Fe}, \mathrm{Ni})_{3} \mathrm{Al} \\
(\mathrm{Fe}, \mathrm{Ni}, \mathrm{Al})\end{array}$ & $\begin{array}{l}\alpha^{\prime \prime} \\
\alpha^{\prime} \\
\alpha^{\prime}{ }_{M} \\
\alpha^{\prime}\end{array}$ & $\begin{array}{l}1,2,3,4,5 \\
1,2,5 \\
1,2,4 \\
1,2,3,4,5\end{array}$ & $\begin{array}{l}2,3,4,5 \\
3,4 \\
3,5 \\
1,2,3,4,5\end{array}$ \\
\hline
\end{tabular}

Fig. 7: $\alpha^{\prime}{ }_{M}$ forms from $\gamma^{\prime}$ induces reversibility; atoms in bcc elementary cells

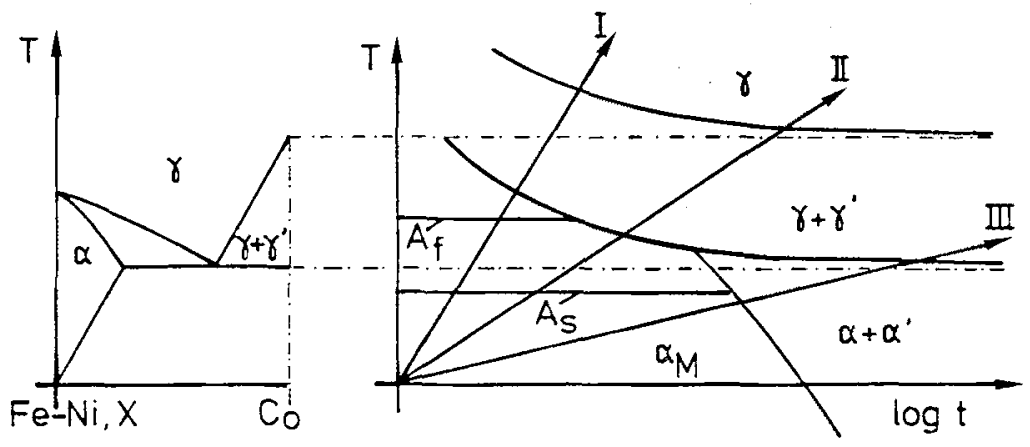

Fig. 8: Time-temperature-transformation diagram for heating of martensite $\alpha$, heating rates $\mathrm{dT} / \mathrm{dt}=\mathrm{T}: \mathrm{T}_{\mathrm{I}}>\mathrm{T}_{\mathrm{II}}>\mathrm{T}_{\mathrm{III}}$

I. Diffusionless reverse $\alpha_{M} \rightarrow \gamma$-transformation complete at $A_{f}$

II. Martensitic reverse transformation interfered by diffusional formation of $\gamma^{\prime}$

III. Precipitation in martensite $\alpha_{M} \rightarrow \alpha+\alpha^{\prime}$ starts before onset of reverse transformation at $\mathrm{A}_{\mathrm{S}}$ 


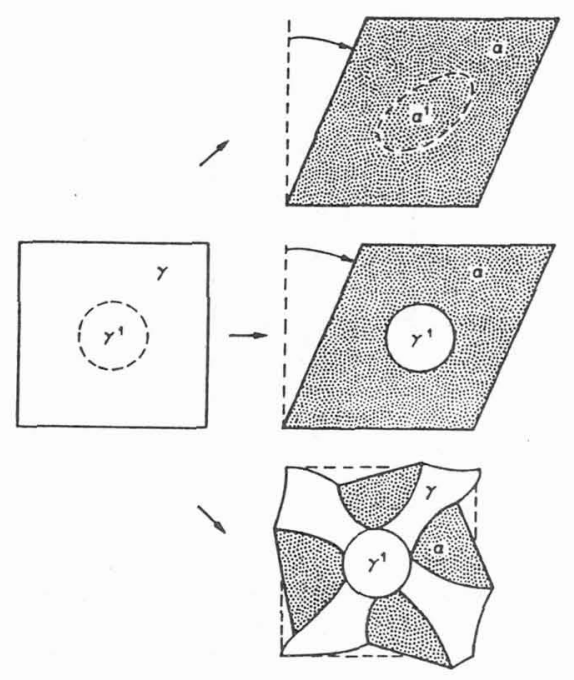

Fig. 9: Martensite transformation of phase mixtures, schematic

a) Formation of $\alpha^{\prime}$ by coherent transformation

b) $\gamma^{\prime}$ stays untransformed and looses coherency

c) martensite crystals form at and between $\gamma^{\prime}$ particles (overaged condition)

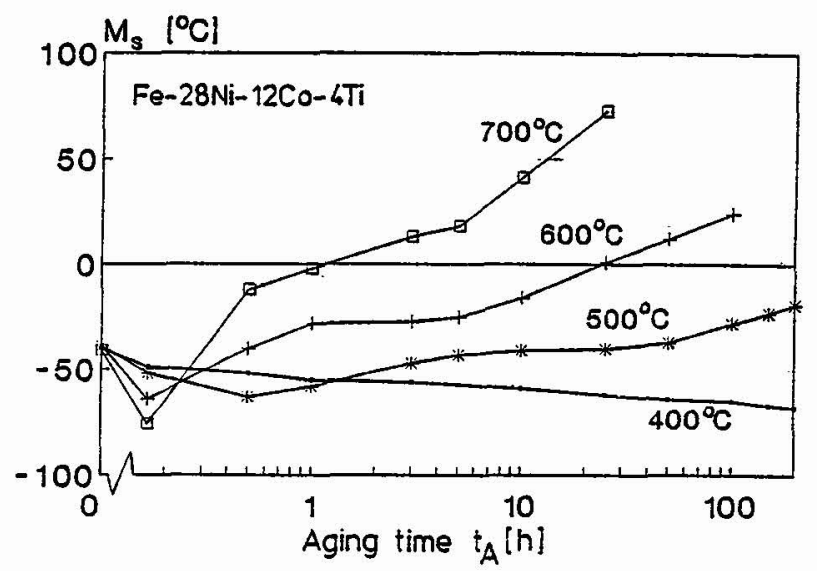

Fig. 10: The effect of ausageing on the martensite start temperature, different ageing temperatures are indicated $\left({ }^{\circ} \mathrm{C}\right)$

$$
\frac{\mathrm{dM}_{\mathrm{s}}}{\mathrm{dt}}=\frac{\delta \mathrm{T}_{0}}{\delta \mathrm{c}} \frac{\delta \mathrm{c}}{\delta \mathrm{t}}+\frac{\delta \Delta \mathrm{T}}{\delta \sigma_{\mathrm{y}}} \frac{\delta \sigma_{\mathrm{y}}}{\delta \mathrm{t}}
$$

The change in chemical composition $\delta \mathrm{c} / \delta \mathrm{t}$ as well as precipitation hardening $\delta \sigma_{\mathrm{y}} / \delta \mathrm{t}$ contribute in such a way that $\mathrm{M}_{\mathrm{S}}$ may rise or fall. For example precipitation of $\mathrm{Ni}$ from $\mathrm{Fe}$ raises the equilibri 
um temperature $T_{0}$ and consequently $M_{s}$, but this effect may be compensated by the impediment of martensite propagation by particles dispersed in the transforming austenite (chpt. 6).16) The precipitation and transformation reactions from heterogeneous austenite can be summarized as follows, (c, nc stand for coherent, non-coherent):

$$
\begin{aligned}
\gamma_{0} & \rightarrow \gamma+\gamma_{\mathrm{c}}^{\prime} \\
\gamma+\gamma_{\mathrm{c}}^{\prime} & \rightarrow \alpha_{\mathrm{M}}+\alpha_{\mathrm{Mc}}^{\prime} \\
\gamma+\gamma_{\mathrm{c}}^{\prime} & \rightarrow \alpha_{\mathrm{M}}+\gamma_{\mathrm{nc}}^{\prime} \\
\gamma+\gamma_{\mathrm{nc}} & \rightarrow \alpha_{\mathrm{M}}+\gamma_{\mathrm{nc}}
\end{aligned}
$$

The structural situation characterized by equ. $9 \mathrm{~b}$ provides the prerequisite for a high degree of reversibility. The most advanced $\mathrm{Fe}$ based shape memory alloys contain Co besides $\mathrm{Ni}$ and $\mathrm{Ti}$ as important alloying elements. They require ausageing for reversibility (Fig. 10, 11). In addition they show an invar behaviour which is of additional use in this context because it minimizes the volume change $\mathrm{v}_{\gamma{ }^{1}}{ }^{162122)}$

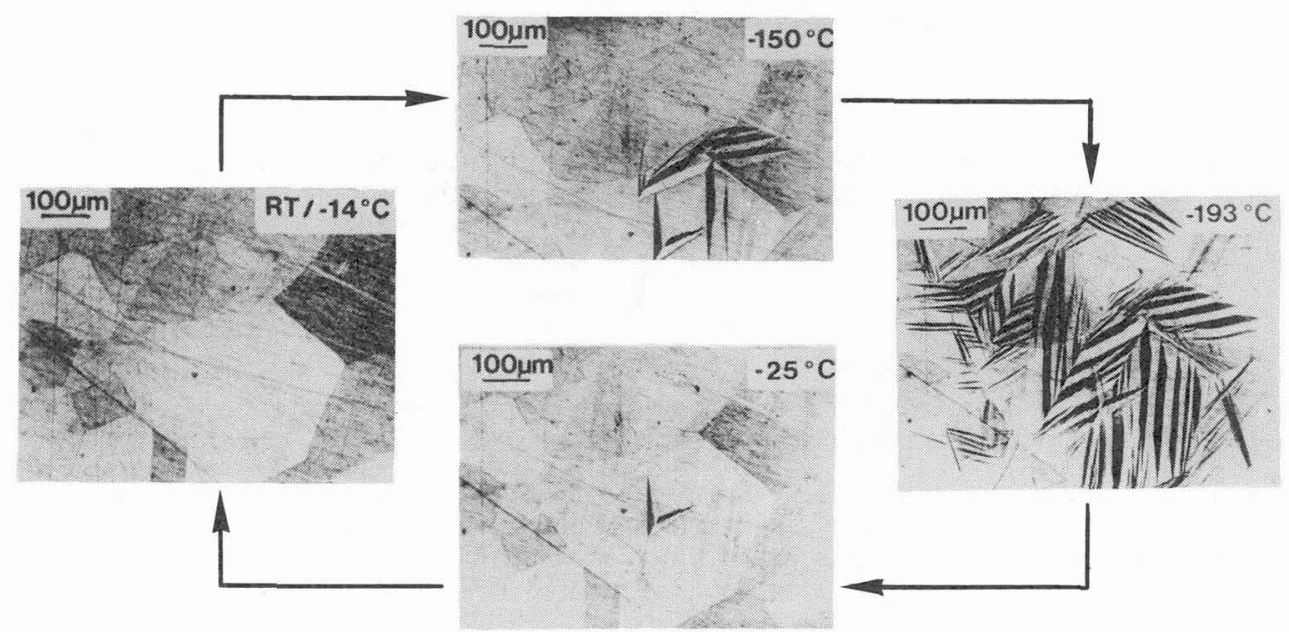

Fig. 11: Sequence of micrographs showing the the complete reversibility of the martensite in an $\mathrm{Fe}-\mathrm{Ni}-\mathrm{Co}-\mathrm{Ti}-\mathrm{alloy}$ during the forward and the reverse transformation

5. Effects of external stress and mechanical properties (yield strength) on $\mathrm{M}_{\mathrm{s}}$

There are effects of external stress as well as of strength (equ. 8) on the martensitic transformations of iron alloys. As they are always associated with shear $\gamma_{\gamma \alpha}$ and volume change $v_{\gamma \alpha}$ two Clausius-Clapeyron equations describe the dependence of the transformation temperatures on shear stress $\tau$ and hydrostatic pressure $\mathrm{p}$ :

$$
\begin{aligned}
& \frac{\mathrm{dM}_{\mathrm{s}}}{\mathrm{d} \tau}=\frac{\gamma_{\gamma \alpha}}{\mathrm{s}_{\gamma \alpha}} \\
& \frac{\mathrm{dM}_{\mathrm{s}}}{\mathrm{dp}}=\frac{\mathrm{v}_{\gamma \alpha}}{\mathrm{s}_{\gamma \alpha}}
\end{aligned}
$$

$\mathrm{s}_{\gamma \alpha}$ is the entropy of transformation (unit: $\mathrm{Jm}^{-3} \mathrm{~K}^{-1}$ ). As the sign of $\Delta \mathrm{v}_{\gamma \alpha}$ is different for $\mathrm{Fe}-\mathrm{Ni}-$ and $\mathrm{Fe}-\mathrm{Mn}$ alloys an opposite pressure dependence is to be expected for the two types of alloys. At $130 \mathrm{kbar}$ the $\epsilon$-phase is formed in pure iron at ambient temperature. 
Strengthening (yield strength $\sigma_{\mathrm{y}}$ ) or elastic softening of the austenite has an effect on $\mathrm{M}_{\mathrm{s}}$ via $\Delta \mathrm{T}$ which is controlled by nucleation and/or propagation of the $\gamma / \alpha$ transformation interface (equ. 1):17)

$$
\mathrm{M}_{\mathrm{s}}=\mathrm{T}_{0}-\frac{\gamma_{\gamma \alpha}{ }^{\sigma} \mathrm{y}}{{ }_{\mathrm{s}} \alpha}=\mathrm{T}_{0}-\Delta \mathrm{T}_{\gamma / \alpha}
$$

Equations 10 and 11 explain for example the dependence of $M_{s}$ on the amount of plastic deformation of austenite. A homogeneous dislocation hardening of the austenite can depress the $\mathbf{M}_{\mathbf{s}}-$ temperature considerably, because of the increasing undercooling $\Delta \mathrm{T}_{\gamma \alpha}$. Highly localized deformation such as slip- and especially shear bands can aid nucleation and therefore increase $M_{\mathrm{S}}$ (Fig. 12).

They will also impede propagation of martensite crystals and therefore reduce the burst phenomenon at $M_{S}{ }^{18}{ }^{19)}$ In solid solutions both the dependence of $T_{0}$ on the chemical composition, and solid solution hardening has to be considered. So it can be understood why elements which must raise $\mathrm{T}_{0}(\mathrm{P}, \mathrm{Si}, \mathrm{V}, \mathrm{Nb}, \mathrm{W})$ lower $\left.\mathrm{M}_{\mathrm{S}}{ }^{17}\right)$

6. Effects of external magnetic fields and magnetism (or antiferromagnetism) in austenite.

The formation of a ferromagnetic phase $(\alpha, f)$ by martensitic transformation of paramagnetic austenite $(\gamma, \mathrm{p})$ is favoured by an external magnetic field $\mathrm{H}$ (equ. 10a):20)

$$
\frac{\mathrm{dM}_{\mathrm{s}}}{\mathrm{dH}}=\frac{\mathrm{B}_{\gamma, \mathrm{p}}-\mathrm{B}_{\alpha, \mathrm{f}}}{\mathrm{s} \gamma \alpha} \mathrm{C}
$$

The analogy of the effects of shear stress $\tau$ (equ. 10a), hydrostatic stress p (equ. 10b), and magnetic field $\mathrm{H}$ is evident. $20 \mathrm{An} \mathrm{Fe}-24.6 \mathrm{Ni}-0.5 \mathrm{C}$ alloy [wt.\%] provides an example for para-magnetic austenite $\gamma_{\mathrm{p}}$ which transforms into ferromagnetic martensite $\alpha_{\mathrm{f}}$ (ZEEMAN effect).

A different situation is encountered, if a magnetic or antiferromagnetic transformation of the austenite interferes with the martensitic transformation. In both $\mathrm{Fe}-\mathrm{Ni}-$ and $\mathrm{Fe}-\mathrm{Pt}$ alloys concentration ranges can be distinguished in which the transformation must start from a paramagnetic or a ferromagnetic austenite. Order in concentrated Fe-Pt alloys lowers $M_{s}$, but raises the Curie temperature $\mathrm{T}_{\mathrm{c}}$ ( Fig. 6). ${ }^{11)}$ To acquire at least a qualitative understanding of the effect of ferromagnetism of martensitic transformation the role of Co additions on $\mathrm{Fe}-\mathrm{Ni}$ alloys is shown in

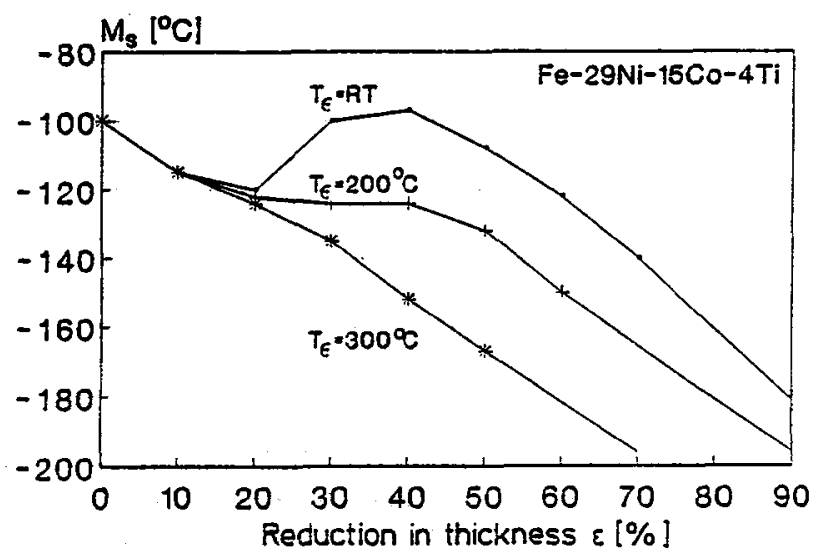

Fig. 12: Influence of the amount of plastic deformation (here: reduction in thickness) on the martensite start temperature, different deformation temperatures are indicated 
Fig. 13. ${ }^{21)}$ This element raises both $\mathrm{T}_{\mathrm{c}}$ and $\mathrm{M}_{\mathrm{S}}$ considerably. It proves that the behaviour of the Fe-Pt alloy must be explained by an overcompensation of the magnetic effect on $M_{s}$ by strengthening due to order (equ. 11). Finally, an anomalous decrease of elastic moduli at $\mathrm{T}<\mathrm{T}_{\mathrm{c}}$ has been reported for ferromagnetic $\mathrm{Fe}-\mathrm{Ni}$ as well as for antiferromagnetic $\mathrm{Fe}-\mathrm{Mn}^{22}$ alloys. Elastic softness of austenite, just as a high yield stress, is a factor which favours reversibility of the transformation because in such a matrix plastic deformations are reduced. The same is true for a reduction of the difference in volume $\Delta \mathrm{v}_{\gamma \alpha}=\mathrm{v}_{\gamma}-\mathrm{v}_{\alpha}$ due to ferromagnetism in the $\gamma$ phase. This may lead to $\Delta \mathrm{v}_{\gamma \alpha} \approx 0$ in some FeNiCo-alloys. ${ }^{23)}$

\section{Summary}

The review of some aspects of martensitic transformation of alloys of iron shows a complex situation. Consequently other alloy systems are better suited for quantitative studies of individual physical features. On the other hand, iron-alloys do provide us with an example of a transformation to which many factors contribute. Those which appear relevant for transformation temperature and reversibility are now summarized:

1. volume change $\mathrm{V}_{\gamma \alpha^{\circ}}: \mathrm{V}_{\gamma \alpha} \neq 0$ disfavours reversibility and lowers $\mathrm{M}_{\mathrm{s}}$, transformation becomes pressure dependent.

2. order in austenite $\mathrm{S}$ : Increasing order induces reversibility and reduces $M_{\mathrm{S}}$.

3. magnetic order in austenite: $\mathrm{M}_{\mathrm{s}}$ can be raised, volume change is reduced and thermoelasticity is induced if $v_{\gamma \alpha} \rightarrow 0$.

4. mechanical strengthening of austenite: $\mathrm{M}_{\mathrm{s}}$ is reduced by all mechanisms which impede formation and propagation of the transformation interface. Reversibility is increased by reduced plastic relaxation or elastic softening of the austenite.

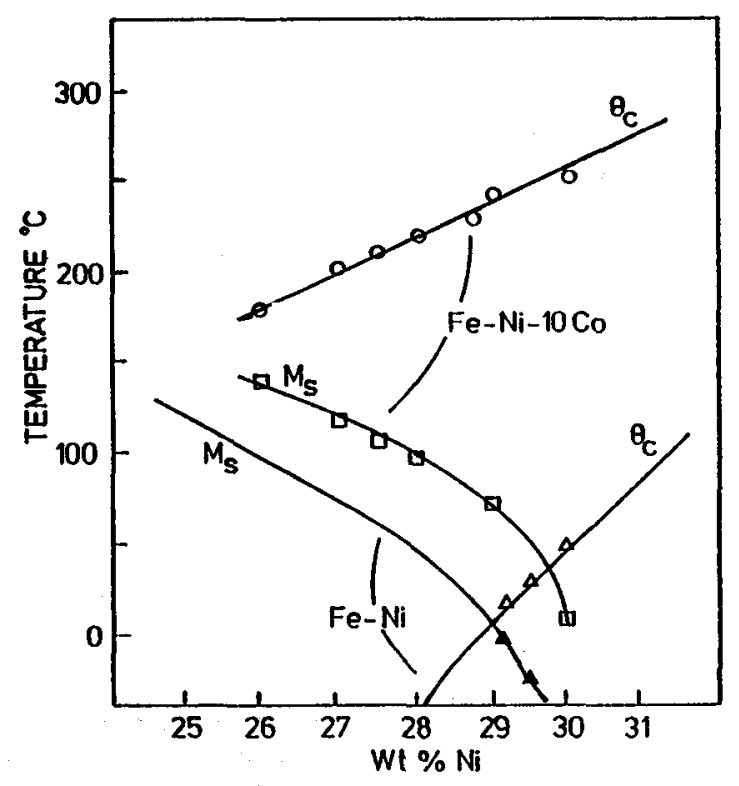

Fig. 13: Change in martensite start temperature and Curie-temperature with Ni-content for both binary $(\mathrm{Fe}-\mathrm{Ni})$ and ternary $(\mathrm{Fe}-\mathrm{Ni}-\mathrm{Co})$ alloys ${ }^{21}$ 
5. lattice invariant shear in martensite: purely elastic deformation or twinning favour reversibility, its absence ( $\mathrm{Fe}-\mathrm{Mn}$ ) retards growth and the completion of the transformation.

6. magnetic order in martensite: the transformation temperature is raised by external fields.

7. temperature: Diffusion should be negligable in the total temperature range up to $A_{f}$.

8. Thermodynamic stability: Massive and bainitic transformation replace the martensitic reaction. Precipitation in $\gamma$ affects the transformation as described in chpt. 4. Segregration to dislocations or twins stabilizes martensite i.e. raises $A_{s}$ and consequently the hysteresis. Precipitation in martensite impedes martensitic reverse transformation.

References

1) Homer, The blinding of Polypheme.

2) CZICHOS, H., in: Proc. of the European Conference on "Martensitic Transformation in Science and Technology", E. Hornbogen, N. Jost (eds.), DGM-Informationsgesellschaft Oberursel, 1989, 3

3) SHIMIZU, K. Trans. Iron and Steel Inst., Japan Vol. II (Proc. ICSTIS), 1971, 1070

4) WAYMAN, C.M., Phase transformations, non diffusive, in: Physical Metallurgy, R. W. Cahn (ed.), Elsevier Science Publishers (1983), 1032

5) COHEN, M. et al., Thermodynamics of the martensitic transformation, in: Thermodynamics in Physical Metallurgy, ASM Cleveland, OH (1952), 242

6) SANDWIK, N.P.J. and WAYMAN, C.M., Met. Trans. 14A (1983), 809, 823, 835

7) WASSERMANN, G., Stahl und Eisen 55 (1935) 1117

8) KESSLER, H. and PITSCH, W., Arch. Eisenhüttenwes. 38 (1967) 321

9) KAJIWARA, S., Phil. Mag. $\underline{39}$ (1979) 325; Phil. Mag. $\underline{41}$ (1980) 403; Phil. Mag. $4 \underline{8}$ (1983) 509

10) SADE, M., HALTER, K. and HORNBOGEN, E., Mat. Sci. Lett. 9 (1990) 112

11) OWEN, S., Mat. Sci. Engg. A127 (1990) 197

12) CAHN, J.W. and ROSENBERG, W., Scripta Met. $\underline{5}$ (1971) 101

13) HORNBOGEN, E. and MEYER, W., Z. Metallkde. 58 (1967) 297

14) HORNBOGEN, E. and MEYER, W., Z. Metallkde. $\underline{58}$ (1967) 372 and 445; Acta Met. 15 (1967) 584

15) MAKI, T. and TAMURA, I., in: Proc. Int. Conf on Martensitic Transformation, ICOMAT 86, Nara, Japan 1986, The Japan Inst. of Metals (1987) 963

16) JOST, N., Proc. Int. Conf on Martensitic Transformation, ICOMAT 89, Sydney, Australia (1989), 446

17) HORNBOGEN, E., Acta Met. 33 (1985) 595

18) JOST, N. and HORNBOGEN, E., J. Mat. Sci. Lett. $\underline{6}$ (1987) 491

19) SKROTZKI, B. and HORNBOGEN, E., Proc. Europ. Symp. on Martensitic Transformation and Shape Memory Properties, Aussois, France, 16.-18.09.1991

20) KINDO, K. et al., Physica B155 (1989) 207

21) DAVIES, R.G. and Magee, C.L., Met. Trans. 1 (1970) 2927

22) HAUSCH, G. and WARLIMONT, H., Z. Metallkde. 63 (1972) 547

23) WASSERMANN, E.F., ACET, M. and PEPPERHOFF, W., J. Magnetism and Magn. Mat. $90 \& 91(1990) 126$

Acknowledgement

Financial support from the German Science Foundatin (DFG Ho325/20) and the Volkswagen Foundation (COSMOS I/63846) is gratefully acknowledged.

Dedicated to Professor Wolfgang Pitsch, Max-Planck-Institut für Eisenforschung, Düsseldorf for his 65. anniversary. 